\title{
Nitrite in breast milk: roles in neonatal pathophysiology
}

Jun Kobayashi, MD, PhD

Department of Clinical Dietetics and Human Nutrition, Faculty of Pharmacy and Pharmaceutical Science, Josai University, Saitama, Japan

Corresponding author: Jun Kobayashi, $\mathrm{MD}, \mathrm{PhD}$

Department of Clinical Dietetics and Human Nutrition, Faculty of Pharmacy and Pharmaceutical Science, Josai University, 1-1 Keyakidai, Sakado, Saitama, 350-0295, Japan

E-mail address: junkoba@josai.ac.jp

Tel: +81-49-271-7223

Fax: $+81-49-271-7223$

\section{Statement of financial support}

No financial assistance was received in support of this study.

\section{Disclosure statement}

The author declares no conflict of interest.

\section{Impact Statement}

- The aim of this review is to discuss the physiological roles of nitrite in breast milk and its implications for neonates.

- Nitrite in breast milk may compensate for the decrease in nitrite during the early neonatal period until the enterosalivary nitrate-nitrite-nitric oxide pathway is established.

- Breast milk rich in nitrite may be effective in the prevention of neonatal infections and gastrointestinal diseases by providing nitric oxide bioavailability.

\section{Category of study}

Review

\section{Author contribution}

J.K. is the sole author of this review article. He rendered efforts to produce the article starting from the idea, collecting the data, drawing figures, creating tables and writing the manuscript. He reviewed and approved the final draft and is solely responsible about the article content.

\section{Patient consent}

Patient consent is not required as this review article does not contain any studies with human subject. 


\begin{abstract}
Dietary nitrate has beneficial effects on health maintenance and prevention of lifestyle-related diseases in adulthood by serving as an alternative source of nitric oxide (NO) through the enterosalivary nitratenitrite-NO pathway, particularly when endogenous NO generation is lacking due to vascular endothelial dysfunction. However, this pathway is not developed in the early postnatal period due to a lack of oral commensal nitrate-reducing bacteria and less saliva production than in adults. To compensate for the decrease in nitrite during this period, colostrum contains the highest amount of nitrite compared with transitional, mature, and even artificial milk, suggesting that colostrum plays an important role in tentatively replenishing nitrite, in addition to involving a nutritional aspect, until the enterosalivary nitrate-nitrite-NO pathway is established. Increasing evidence demonstrates that breast milk rich in nitrite can be effective in the prevention of neonatal infections and gastrointestinal diseases such as infantile hypertrophic pyloric stenosis and necrotizing enterocolitis, suggesting that breastfeeding is advantageous for newborns at risk, given the physiological role of nitrite in the early postnatal period.
\end{abstract}




\section{INTRODUCTION}

Recent evidence suggests that dietary nitrate and nitrite serve as an alternative source of nitric oxide (NO); it has initiated a paradigm shift from considering nitrate and nitrite as inert endproducts of NO to the realization that they are key regulators for several physiological roles in preventing lifestylerelated diseases in adulthood (1).

However, little is known about the preventive effects of dietary nitrate and nitrite on diseases in the neonatal period. For neonates, milk is the only nutrition source. Breast milk, particularly colostrum, contains the highest amount of nitrite compared with transitional, mature, and even artificial milk (2). While the immunological and nutritional benefits of breastfeeding have been well documented (3), the physiological significance of nitrate and nitrite in breast milk for neonates remains unclear. When considering the conversion of dietary nitrate and nitrite to NO bioactivity in relation to neonatal physiology, a high nitrite concentration in breast milk may have some physiological implications for neonates. This review aims to discuss the physiological roles of dietary nitrite in the early neonatal period, particularly focusing on the bioactivation of nitrite in breast milk and its preventive effects on infectious and gastrointestinal diseases frequently encountered in early infancy.

\section{NITRATE AND NITRITE IN BREAST MILK AND THEIR SAFETY}

Excess dietary nitrate and nitrite in infants are related to methemoglobinemia (blue-baby syndrome), in which the nitrite-mediated oxidation of ferrous iron $\left(\mathrm{Fe}^{2+}\right)$ in hemoglobin $(\mathrm{Hb})$ to the ferric state $\left(\mathrm{Fe}^{3+}\right)$ causes hypoxia and cyanosis, resulting in blue skin color $(4,5)$. Infants younger than 6 months old are susceptible to nitrate-induced methemoglobinemia due to easy oxidation of fetal $\mathrm{Hb}$ by reaction with nitrite (6) and an immature methemoglobin (metHb) reductase system $(7,8)$. In addition to these physiological conditions in neonates, in the reported cases of blue-baby syndrome, the infants were fed formula milk prepared with well water contaminated with excess nitrate (derived from fertilizers, approximately $10-66 \mathrm{mg} / \mathrm{L}$ of nitrate in water) that can be reduced to large amounts of nitrite (5). A considerable amount of nitrite may have been loaded in these infants, leading to methemoglobinemia. Based on the lessons and subsequent analyses of the infant cases of methemoglobinemia, the World Health Organization (WHO) announced that the acceptable daily intake (ADI) for nitrate and nitrite for humans was 3.7 and $0.06 \mathrm{mg} / \mathrm{kg}$ body weight (BW)/day, respectively, which were derived from the data calculated from the doses of $<500 \mathrm{mg} / \mathrm{kg} \mathrm{BW} /$ day of sodium nitrate that were harmless to rats and dogs (9).

Regarding infants solely dependent on milk feeding for their nutrition, they ingest some nitrate and nitrite from breast milk $(0.19$ and $0.08 \mathrm{mg} / 100 \mathrm{~mL}$, respectively) and formula milk $(0.02-3.48$ and 0.00005-0.03 mg/100 mL, respectively) (8). However, these intakes are within the ranges that do not cause clinical problems because the doses are far lower than the reported amounts of nitrate and nitrite from the well water contaminated with fertilizers. As long as the water for milk preparation is not bacterially contaminated, the absorbed nitrate that has not been converted to nitrite can be readily excreted in the urine without adverse effects (10). Even if the mother ingests water with very high 
nitrate concentrations (up to $100 \mathrm{mg} / \mathrm{L}$ ), they are not reflected in breast milk (11), suggesting that breastfeeding infants are generally not at risk of methemoglobinemia (12).

\section{PHYSIOLOGICAL ROLES OF DIETARY NITRATE AND NITRITE IN THE GENERATION OF NO BIOACTIVITY}

Dietary nitrate abundant in green leafy vegetables is absorbed from the upper gastrointestinal tract into systemic circulation, and approximately $60 \%$ is excreted via the kidney within $48 \mathrm{~h} \mathrm{(13).} \mathrm{However,}$ $25 \%$ of nitrate is actively taken up from circulation by the salivary gland and secreted into saliva. This salivary nitrate is reduced to nitrite by commensal bacteria residing on the surface of the tongue (14). Then, the salivary nitrite is swallowed to the acidic stomach, protonated to form nitrous acid, followed by gastric NO generation or reentering into circulation as nitrite from the upper gastrointestinal tract to form the nitrite pool in the blood and tissues (referred to as enterosalivary nitrate-nitrite-NO pathway) (15). NO bioactivities, such as blood pressure reduction, correspond with the point of peak plasma nitrite concentration, suggesting that basal nitrite levels in the blood are significant contributors to NO bioactivity (16).

There are two sources of nitrite in whole blood and tissues (Fig. 1). The endothelial NO synthase (eNOS)-derived NO accounts for a significant portion of endogenously produced nitrite because plasma nitrite levels decrease by $70 \%$ by eNOS knockout in fasting mice $(17,18)$. However, dietary nitrate and nitrite also contribute to $30 \%-50 \%$ of the circulating pool of these anions, as evidenced in the experiment using nitrate- and nitrite-deficient diets (19). The nitrite in the pool is transduced to NO bioactivity by circulating and tissue-bound nitrite reductases (1). Several mechanisms to reduce nitrite to NO have been reported, including enzymatic reduction by xanthine oxidase, NO synthase, components of the mitochondrial electron transport chain, and nonenzymatic acidic disproportionation (20). However, these mechanisms require low $\mathrm{pH}$ and oxygen saturation, particularly in pathological conditions; therefore, they do not readily work under physiological hypoxia. However, the role of erythrocytes as a physiological transporter of NO bioactivity has garnered attention recently. Nitritemediated inhibition of platelet activation requires the presence of erythrocytes; nitrite has no effect in the absence of erythrocytes. This action is abrogated by a NO scavenger (21). Tsuchiya et al. showed that the dietary isotope of nitrite $\left({ }^{15} \mathrm{NO}_{2}{ }^{-}\right.$in drinking water) is taken up by erythrocytes and forms Fe${ }^{15} \mathrm{NO} \mathrm{Hb}$ in circulation with subsequent improvement of renal injuries caused by nitro-L-arginine methyl ester hydrochloride (L-NAME, an NOS inhibitor)-induced hypertension in rats (22). These results suggest that erythrocyte-associated nitrite bioactivation may be mediated through NO and subsequent $\mathrm{NO}-\mathrm{Hb}$ formation.

Nitrite in erythrocytes is reduced to $\mathrm{NO}$ by $\mathrm{Hb}$, which is deoxygenated during artery-to-vein transit, resulting in NO release to other thiol acceptors (cysteine and glutathione) to form plasma and other cellular protein $S$-nitrosothiols (SNOs), which are vasoactive at concentrations as low as 1-5 nM (23, 24), and convey the NO signal to the vessel walls as well as other peripheral tissues and organs. However, considering the rapid and strong scavenging of $\mathrm{NO}$ by $\mathrm{Hb}$ in erythrocytes, the question arises 
as to how NO bioactivity escapes the erythrocytes. Once NO is formed in the erythrocytes, it must escape rapid scavenging by the intra-erythrocytic $\mathrm{Hb}$. Many hypotheses have been proposed, such as nitrite reduction being limited to erythrocyte membrane compartments and production of another stable species, including nitrosothiol or $\mathrm{N}_{2} \mathrm{O}_{3}$ (a potent $S$-nitrosating agent) formation. Stamler et al. have reported that the erythrocyte-dependent vasodilation mechanism is related to the nitrosation of conserved Cys93 residue in the $\mathrm{Hb} \beta$-chain ( $S$-nitrosated $\mathrm{Hb}$ [SNO-Hb] formation) by $\mathrm{NO}$ transfer from $\mathrm{Fe}-\mathrm{NO} \mathrm{Hb}$ (24). Roche et al. reported that $S$-nitrosothiol formation such as $S$-nitrosoglutathione could occur through a metHb-nitrite-mediated $\mathrm{N}_{2} \mathrm{O}_{3}$ formation, and serve as a source of erythrocytederived and exportable bioactive NO (25). Other reports also propose a mechanism in which an increased affinity of metHb-NO or $\mathrm{Hb}_{-} \mathrm{NO}^{+}$for the erythrocyte membrane could lead to $\mathrm{NO}$ escape through nitrosylation of anion exchange protein (AE1)(26), suggesting a role of nitrosation of erythrocyte membranes in the escape of NO bioactivity.

Although there may be other biochemical pathways of nitrite bioactivation that remain to be discovered, the detailed in vivo research is now ongoing (27-31), and further discussion will not be covered in this review.

\section{POSTNATAL DECREASE IN PLASMA NITRITE LEVELS}

In contrast to adults in whom the enterosalivary nitrate-nitrite-NO pathway is already being established, some consideration may be needed to determine whether this pathway is available in neonates (32). In animal models, the plasma nitrite levels in fetal sheep fall immediately after umbilical cord ligation and initiation of pulmonary ventilation (more than $60 \%$ decrease in plasma nitrite levels within 15 min after birth) (Fig. 2) (33). In humans too, the plasma nitrite levels in neonates rapidly fall at birth (from $0.18 \pm 0.02$ to $0.08 \pm 0.02 \mu \mathrm{mol} / \mathrm{L}$ ) and remains lower than those in adults for the first few weeks of life (34). This may be associated with dramatic circulatory changes from the placental to pulmonary circulation at birth $(33,34)$. Several reasons may account for this physiological decrease in plasma nitrite levels. First, the placental tissue constitutes a significant source of nitrite toward the fetus that is lost immediately after umbilical cord ligation at birth $(6,33)$. The second reason may be the reaction of NO with superoxide generated by oxygenation to form peroxynitrite following pulmonary respiration. The peroxynitrite generated at birth not only prevents newborns from bacterial infection, but also scavenges NO away from nitrite generation $(35,36)$, possibly reflecting a rapid decrease in the plasma nitrite levels in newborns after birth.

In addition to the circulatory and respiratory changes at birth, other factors also lower the plasma nitrite levels in the neonatal periods due to the immature enterosalivary nitrate-nitrite-NO pathway (34). First, the nitrate levels in milk and formula are lower than in foods in adulthood, resulting in less nitrate ingestion in infants $(0.12 \mathrm{mg} / \mathrm{kg} \mathrm{BW} /$ day $)$ than in adults $(0.7 .3 .0 \mathrm{mg} / \mathrm{kg} \mathrm{BW} /$ day $)$. Second, the saliva production rates are lower in newborns than in adults. Third, nitrate reduction to nitrite in the oral cavity by commensal bacteria is approximately ten-fold less in neonates than in adults. Fourth, the newborn stomach produces much less NO from swallowed nitrite than that of adults due to high 
gastric $\mathrm{pH}$. Fifth, newborn urinary nitrite concentrations are significantly higher than those of the adult (33), possibly because of the lack of carbonic anhydrase-mediated reabsorption of nitrite in the newborn kidney (37). Therefore, these factors that occur after birth may physiologically reduce NO bioactivity during the first weeks of the neonatal period (Fig. 3).

\section{BREAST MILK MAY COMPENSATE FOR NITRITE DECREASE IN THE EARLY POSTNATAL PERIOD}

Because the endogenous reduction of nitrate to nitrite is absent in the early postnatal period (38), the enterosalivary nitrate-nitrite-NO pathway, which contributes to forming a stable nitrite pool in the blood (Fig. 1), has not yet been established immediately after birth (32). Therefore, breast milk rich in nitrite may be necessary to replenish nitrite to compensate for the decrease in nitrite in the early postnatal period.

Breast milk is the most perfect food for infants, but the nutritional quality and characteristics of breast milk change over time. Colostrum contains immune-protective factors (e.g., secretory immunoglobulin IgA, lactoferrin, leukocytes, and epidermal growth factor), which are more concentrated in the colostrum of mothers who deliver preterm infants (39). Considering that colostrum contains lower lactose concentrations than mature breast milk, its primary function is likely to be immunological rather than nutritional (40). Colostrum contains higher nitrite and lower nitrate concentrations than transition and mature breast milk (Table 1). According to the human study by Hord (2), the mean nitrite concentrations are $0.08 \pm 0.02 \mathrm{mg} / 100 \mathrm{~mL}$ in colostrum and $0.001 \pm 0.001 \mathrm{mg} / 100 \mathrm{~mL}$ in transition and mature breast milk (Tables 1), giving the average daily nitrite intake of $0.2 \mathrm{mg} / \mathrm{mg} / \mathrm{kg} \mathrm{BW} /$ day in colostrum and $0.0027 \mathrm{mg} / \mathrm{kg} \mathrm{BW} /$ day in transition and mature breast milk (as calculated according to $3.0 \mathrm{~kg} \mathrm{BW}$ and $750 \mathrm{~mL} /$ day, commonly used reference volume of intake in infants based on the study of the US Food and Nutrition Board, Institute of Medicine, National Academy of Science) (41) (Tables 2).

Iizuka et al. also measured the nitrite and nitrate concentrations in the breast milk collected from Japanese women on postpartum days 2-5, which showed 19.3-82.4 $\mu \mathrm{M} / \mathrm{L}$ (mean $\pm \mathrm{SD}$, $43.6 \pm 5.3 \mu \mathrm{M} / \mathrm{L}$ ) of nitrite, significantly higher than that in commercial formula milk (ranging from 8.4 to $25.5 \mu \mathrm{M} / \mathrm{L}$ [mean $\pm \mathrm{SD}, 14.2 \pm 5.3 \mu \mathrm{M} / \mathrm{L}$ ] of nitrite). Although the Joint Food and Agricultural Organization/WHO has set the ADI for the nitrate and nitrite ions at 3.7 and $0.06 \mathrm{mg} / \mathrm{kg} \mathrm{BW} /$ day, respectively, when taking an average nitrite concentration of $43.6 \mu \mathrm{M} / \mathrm{L}$ (or $2.0 \mathrm{mg} / \mathrm{L}$ ) in colostrum (42), the total daily nitrite exposure to nursing infants is roughly $0.5 \mathrm{mg} / \mathrm{kg} \mathrm{BW} /$ day (assuming the daily intake of breast milk is approximately $250 \mathrm{~mL} / \mathrm{kg} \mathrm{BW}$ ) or 8.3 -fold higher than the ADI for nitrite (Table 2). Exceeding the ADI limits with the usual intake levels of breast milk indicates that these regulatory limits may not have a rational basis when applied to food sources of nitrate and nitrite for early infants. Higher nitrite concentrations in colostrum may be for temporary assistance until dietary nitrate in the milk can be effectively processed via the enterosalivary pathway, which may play an important role in adaptation to the gastrointestinal, respiratory, and circulatory systems in the perinatal 
period (discussed later). Kanematsu et al. demonstrated that in rats fed with dietary nitrite, renal injuries caused by L-NAME-induced hypertension significantly improved (43). The dietary dose of nitrite used in this study $(0.1$ and $1.0 \mathrm{mg} / 100 \mathrm{~mL}$ of nitrite in drinking water) and amount of nitrite the rats drank $(0.1$ and $1.0 \mathrm{mg} / \mathrm{kg} \mathrm{BW} /$ day, respectively, calculated as $300 \mathrm{~g}$ of BW and $30 \mathrm{~mL}$ of water intake/day) are almost equivalent to the dose in human colostrum and daily nitrite consumption of neonates in the study by Iizuka $(0.2 \mathrm{mg} / 100 \mathrm{~mL}$ in colostrum and $0.5 \mathrm{mg} / \mathrm{kg} \mathrm{BW}$ /day intake) (Table 2).

However, for convenience, daily intakes of nitrite/nitrate in breast milk ( $\mathrm{mg} / \mathrm{kg} / \mathrm{day})$ presented here are the calculated amounts. Therefore, the actual intake of breast milk varies among individuals and possibly with a tendency of smaller intake in the early postnatal period than thereafter. In Iizuka's study (42), NO production in the stomach during each intake of breast milk was obviously higher than that of formula milk (Fig. 4), suggesting that the physiological amounts of nitrite in human colostrum are a source of NO and may be relevant to the subsequent generation of NO metabolites in the stomach, as well as NO bioavailability in the systemic circulation (43).

In this short review, taking into account the fact that the nitrite in colostrum increases temporarily, we will discuss how colostrum of breast milk, rich in nitrite is physiologically involved in the transitions from the fetus to the newborn at birth.

\section{CLINICAL IMPLICATIONS OF NITRITE IN BREAST MILK FOR INFANT NURSING}

Until the oral flora settles in early infancy, high nitrite levels in breast milk may play important roles in the physiological adaptation to extrauterine life. Recent research has provided scientific evidence for promoting breastfeeding to prevent diseases frequently encountered in early infancy.

\section{Prevention of Postnatal Infections}

The sources of nitrate and nitrite in breast milk are not well known. The amount of nitrate ingested by the mother does not affect the nitrate concentration in the breast milk, suggesting that active regulation of nitrate transport exists in the mammary tissues. However, xanthine oxidase (XO) in breast milk is important for NO generation (44). XO is a cellular redox enzyme homologous to bacterial nitrate reductase and is highly expressed in mammary epithelial cells. During lactation, these cells synthesize milk fat globules that are packaged by a membrane consisting of phospholipids and XO. XO, which is highly expressed in the globules in the first few weeks postpartum, can produce superoxide and hydrogen peroxide in the catalytic process of hypoxanthine to uric acid using oxygen as an electron acceptor (45). XO can produce NO using nitrate and nitrite as electron acceptors, leading to the subsequent generation of peroxynitrite, a potent bactericidal oxidant, following the combination of NO and superoxide (46). Stevens et al. showed XO-mediated antibacterial properties in breast milk against Escherichia coli and Salmonella enteritidis in an in vitro culture study (47). These reactive oxygen species (ROS) and reactive nitrogen species are generated during lactation with antimicrobial properties in the breast milk and gastrointestinal tracts, which may be required in the neonatal period 
when neonates are vulnerable to various infections. This period coincides with the high nitrite levels in breast milk and provides potent protection from microbial infections, particularly in the period when the neonatal stomach is less acidic, ranging between $\mathrm{pH} 4$ and $\mathrm{pH} 6$ for the first few days after birth (48).

Iizuka et al. analyzed the intragastric generation of $\mathrm{NO}$ gas in neonates fed with breast or formula milk. They collected stomach gas $1 \mathrm{~h}$ after feeding once daily for 1-5 days postpartum to measure NO using a chemiluminescence NO analyzer (42). They showed that the NO levels in the stomach gas of neonates fed only breast milk were significantly higher than those of neonates fed formula milk with or without supplementary breast milk with a peak on postpartum days 2 to 5 (6.03 \pm 5.73 vs. $2.24 \pm 15.71 \mathrm{ppm}$, respectively), suggesting that NO generation by breast milk plays important roles not only in achieving bactericidal activities but also in regulating gastric mucosal blood flow and mucus formation.

\section{Effects of nitrite in breast milk on the gastrointestinal tract}

\section{Infantile Hypertrophic Pyloric Stenosis}

Another disease in early infancy relevant to feeding practice is infantile hypertrophic pyloric stenosis (IHPS). Although IHPS may be reportedly caused by several variables, including genetic, environmental, and mechanical factors (49-51), several studies have reported that NO deficiency in the gastric pylorus is significantly involved in the onset of IHPS (52). Nitrite in breast milk may play an important role in regulating gastric motility and tone of the pyloric sphincter in the stomach.

The mouse model lacking the nNOS gene showed marked enlargement of the stomach with hypertrophy of the pyloric sphincter and circular muscle layer (53). Chung et al. showed the etiological role of the gene for nNOS in IHPS, suggesting that nNOS is a susceptibility locus for this lesion (54). Barbosa et al. administered L-NAME to pregnant rats and their newborns, demonstrating that newborns exhibited IHPS (55). As for humans, Abel reported reduced nNOS expression in the pyloric muscle layers and myenteric plexus obtained from the patients with IHPS using immunohistochemical staining. Kusafuka also reported that the transcriptional levels of nNOS were reduced in IHPS specimens compared with controls (56). Huang further observed that plasma nitrite levels were significantly lower in patients with IHPS than in controls (53).

Although epidemiological studies have not so far revealed the evidence that NO deficiency is the direct cause of IHPS, an increased risk of IHPS is significantly observed in formula-fed infants compared with breast-fed infants (57). Krogh et al. also reported that bottle-fed infants experienced a 4.6-fold higher risk of IHPS compared with infants who were not bottle-fed and emphasized the advantage of exclusive breastfeeding in the first month after birth to prevent IHPS development (58). These findings suggest that stomach and pyloric relaxation are dependent on NO generation, at least during early infancy, and its absence is significantly associated with pyloric muscle hypertrophy (50), which frequently occurs in a couple of weeks after birth. It can be established in future studies whether nitrite concentration in breast milk is directly involved in the prevention of the development 
of IHPS.

\section{Necrotizing Enterocolitis and Transfusion-Related Acute Gut Injury}

Necrotizing enterocolitis (NEC) is characterized by decreased gastrointestinal blood flow and pathogenic bacterial invasion following the breakdown of the mucus barrier lining the lumen of the gut. In particular, neonates born at extremely low gestational ages have a strong tendency to be exposed to ischemia of the gastrointestinal tract during periods of increased oxygen demand (e.g., enteral feeding), which is likely to cause ischemia-related acute gut injury in premature infants (59). Although prematurity is the leading risk factor for NEC development, breastfeeding has been demonstrated as the most important protective strategy against NEC (60). While there are several components in breast milk that are thought to be protective in preventing NEC, including lactoferrin, various growth factors, and non-digestible carbohydrates, leading to normal microbial colonization of the gut $(61,62)$, Yazji et al. showed that NO bioactivity is endogenously decreased due to toll-like receptor 4-mediated reduction of eNOS expression in the mouse model suffering from NEC. They also demonstrated that the addition of nitrate and nitrite to the formula milk significantly restored intestinal microcirculation, decreased the amount of pro-inflammatory cytokine expression in the intestine, and reduced the NEC severity of this model through the dietary nitrate-nitrite-NO pathway (63). This study provides a practical insight into the protective mechanism of breast milk against this disease and suggests that NO transfer via dietary nitrite is clinically involved in NO bioavailability, including vasodilatory effects in the gastrointestinal system.

Recent studies have further reported that the transfusion of premature infants with anemia causes transfusion-related acute gut injuries, including NEC (64). Because the intestinal microvascular blood flow in premature infants with anemia is dependent on NO-based hypoxic vasodilation, decreased NO utilization in the intestinal blood perfusion by erythrocytes may be responsible for the onset of NEC. A recent growing body of evidence suggests that the effects of processing and storage on erythrocytes not only significantly decrease the SNO-Hb content and erythrocyte-dependent vasodilatory activity (65), but also, on the contrary, increased hemolysis and NO scavenging by cell-free Hb, which scavenges NO about 400 times faster than erythrocyte-encapsulated $\mathrm{Hb}$ due to the absence of a diffusion barrier between plasma and the interior of the erythrocyte (66), consequently leading to vasoconstriction of blood transfusion, whereas these defects were reversed by repletion of $\mathrm{SNO}-\mathrm{Hb}$ (65). In addition to the role of erythrocytes in NO transfer, erythrocytes have eNOS activity, which endogenously generates NO bioactivity from L-arginine (67), whereas L-arginine in erythrocytes is eliminated by arginase, whose activity is enhanced according to the storage period of blood $(68,69)$. This evidence suggests that $\mathrm{Hb}$-mediated NO transfer plays an important role in preventing microcirculatory failure of the gastrointestinal tract and explains why breast milk rich in nitrite can be effective in these pathological conditions. However, Patel et al. suggested that among very low birth weight (VLBW) infants, severe anemia, but not erythrocyte transfusion, was associated with an increased risk of NEC (70). Although they did not assess NO metabolites in erythrocytes (e.g., SNO- 
$\mathrm{Hb}$ ), unknown factors may still be involved in the onset of NEC. Further advanced studies may be needed to directly determine whether NO scavenging by stored RBCs is relevant to the risk of NEC.

\section{Possibility of Systemic Effects of Nitrite in Breast Milk}

Neonates are physiologically at risk of hypoxic and ischemic insults during delivery, after which they are exposed to a high-oxygen environment following the onset of pulmonary ventilation. Nitrite may confer systemic protection against this physiological oxidative stress owing to increasing evidence that nitrite is protective in adult models of ischemia/reperfusion injury. (71-74). Nitrite is thought to lead mitochondria to efficient oxygen utilization by inhibiting the activity of complex I of the electron transport chain via $S$-nitrosation, effectively decreasing mitochondrial ROS generation and subsequent cell damage (19). NO and other bioactive nitrogen oxide species involved in this process are produced in hypoxic and ischemic conditions from nitrite in the blood and tissues by the reaction with a number of metal-containing proteins with nitrite-reducing activity present in most of the cells, such as deoxygenated myoglobin and $\mathrm{Hb}$, cytoglobin, neuroglobin, mitochondrial enzymes, $\mathrm{XO}$, cytochrome P450, and eNOS (20). Therefore, increased nitrite levels in circulating blood and tissues may be enough to cause systemic protection from oxidative stress at birth.

Although the effect of nitrite supplementation on systemic organs such as the lungs and heart is yet to be studied in the neonatal period, the treatment of persistent pulmonary hypertension of the newborn with inhaled NO reportedly increased the nitrite levels in the blood at least twofold, reaching approximately $300 \mathrm{nM} / \mathrm{L}$ (75); this concentration has been reported to have systemic effects, including protection of mice from hepatic infarct, increase in blood flow in the human forearm, and decrease in the systolic blood pressure in adults (34). Although the therapeutic effect of inhaled NO was initially believed to be confined to lung lesions, in the 1990s, there were reports that inhaled NO could inhibit platelet aggregation, followed by publications demonstrating a wide range of systemic effects of inhaled NO, such as the ability to decrease ischemia-reperfusion injuries of the heart and mesentery, thrombosis, and leukocyte adhesion and modulate systemic vascular tone (76). Ibrahim et al. reported that inhaled NO therapy increased the blood concentrations of nitrite, nitrate, and SNO-Hb in infants with pulmonary hypertension, the concentrations of which may be achievable with dietary supplementation of nitrite. Therefore, they speculated that these stable nitrogen oxide compounds, even if they are derived from diets or inhaled NO, may be carriers of NO-mediated activities circulating throughout the body and account for beneficial effects on the brain, heart, and other critical organs (75). Further studies are needed to confirm that dietary nitrite in breast milk may be directly associated with the protection of systemic organs from oxidative insults following physiological transfer from the fetus to the neonate.

\section{Nursing of premature infants in neonatal intensive care units}

Separate consideration of nitrite intake would be needed for nursing of premature infants in neonatal intensive care units (NICU). Newborn infants in NICU are fed with widely varying concentrations of 
nitrate and nitrite. Nitrite intake is limited for preterm infants compared with term infants in NICU where initial feeds may be delayed and formula milk with lower nitrite concentrations may be given. Even if breast milk is given, the nitrite concentrations in the breast milk of mothers of premature infants are significantly lower than those of mothers of term infants (77). Furthermore, nitrite intake decreases by $50 \%-75 \%$ due to storage and freeze-thawing of breast milk prior to ingestion because nitrite is oxidized to nitrate by lactoperoxidase, resulting in a decrease in nitrite bioavailability by the time of feeding. The intake of nitrate and nitrite from parenteral nutrition may be lower than that from breast milk (77).

Although NICU may be the place where an increase in NO bioavailability from nitrite has to be considered preferentially for premature infants, there have not been, so far, enough data and discussion to precisely resolve this issue. Therefore, further clinical research will be performed to determine the beneficial effects of nitrite in the breast milk for the nursing of preterm infants in the NICU.

\section{CONCLUSION}

At birth, although neonates experience the most dramatic environmental shift from intrauterine to extrauterine life, their respiratory, circulatory, and metabolic systems can adapt efficiently to the new environment. NO may be involved in this physiological process to help the successful adaptation to environmental changes. Although the effectiveness of nitrite intake in the neonatal period compared to that in adults with various lifestyle-related diseases remains unclear, nitrite in breast milk in early infancy appears to compensate for the lack of the enterosalivary-nitrate-nitrite-NO pathway. More detailed research should be carried out focusing on the contribution of nitrite in breast milk to NO bioactivity in neonatal physiology and pathophysiology. Hopefully, this review will stimulate the development of research in this area and contribute to the promotion of breastfeeding. 


\section{REFERENCES}

1. Kobayashi, J., Ohtake, K., Uchida, H. NO-rich diet for lifestyle-related diseases. Nutrients 7, 49114937 (2015).

2. Hord, N. G., Ghannam, J. S., Garg, H. K., Berens, P. D., Bryan, N. S. Nitrate and nitrite content of human, formula, bovine, and soy milks: implications for dietary nitrite and nitrate recommendations. Breastfeed. Med. 6, 393-399 (2011).

3. Field, C. J. The immunological components of human milk and their effect on immune development in infants. J. Nutr. 135, 1-4 (2005).

4. Comly, H. Cyanosis in infants caused by nitrates in well water. JAMA 129, 112-116 (1945).

5. Knobeloch, L., Salna, B., Hogan, A., Postle, J., Anderson, H. Blue babies and nitrate-contaminated well water. Environ. Health Perspect. 108, 675-678 (2000).

6. Blood, A. B., et al. Increased nitrite reductase activity of fetal versus adult ovine hemoglobin. Am. J. Physiol. Heart Circ. Physiol. 296, H237-H246 (2009).

7. Power, G. G., et al. A nobel method of measuring reduction of nitrite-induced methemoglobin applied to fetal and adult blood of humans and sheep. J. Appl. Physiol. 103, 1359-1365 (2007).

8. Berens, P. D., Bryan, N. S. Nitrite and nitrate in human breast milk: implications for development. In: Nitrite and Nitrate in Human Health and Disease (Bryan, N. S. \& Loscalzo, J., eds) 141-152 (Humana Press, Cham, 2017).

9. European Food Safety Authority. Nitrate in vegetables: scientific opinion of the panel on contaminants in the food chain. EFSA J. 689, 1-79 (2008).

10. Phillips, W. E. Naturally occurring nitrate and nitrite in foods in relation to infant methemoglobinaemia. Food Cosmet. Toxicol. 9, 219-228 (1971).

11. Dusdieker, L. B., Stumbo, P. J., Kross, B. C., Dungy, C. I. Does increased nitrate ingestion elevate nitrate levels in human milk? Arch. Pediatr. Adolesc. Med. 150, 311-314 (1996).

12. Greer, F. R., Shannon, M. Infant methemoglobinemia: the role of dietary nitrate in food and water. Pediatrics 116, 784-786 (2005). 
13. Wargner, D. A., Schultz, D. S., Deen, W. M., Young, V. R., Tannenbaum, S. R. Metabolic fate of an oral dose of $15 \mathrm{~N}$-labeled nitrate in humans: Effect of diet supplementation with ascorbic acid. Cancer Res. 43, 1921-1925 (1983).

14. Lundberg, J. O., Weitzberg, E., Lundberg, J. M., Alving, K. Intragastric nitric oxide production in humans: Measurements in expelled air. Gut 35, 1543-1546 (1994).

15. Lundberg, J. O., Weitzberg, E., Gladwin, M. T. The nitrate-nitrite-nitric oxide pathway in physiology and therapeutics. Nat. Rev. Drug Discov. 7, 156-167 (2008).

16. Kapil, V., et al. Inorganic nitrate supplementation lowers blood pressure in humans: role for nitritederived NO. Hypertension 56, 274-281 (2010).

17. Milsom, A. B., Fernandez, B. O., Garcia-Saura, M. F., Rodriguez, J., Feelisch, M. Contributions of nitric oxide synthases, dietary nitrite/nitrate, and other sources to the formation of NO signaling products. Antioxid. Redox Signal 17, 422-432 (2012).

18. Kleinbongard, P., et al. Plasma nitrite reflects constitutive nitric oxide synthase activity in mammals. Free Radic. Biol. Med. 35, 790-796 (2003).

19. Waltz, P., Escobar, D., Botero A. M., Zuckerbraun, B. S. Nitrate/nitrite as critical mediators to limit oxidative injury and inflammation. Antioxid. Redox Signal. 23, 328-239 (2015).

20. Kim-Shapiro, D. B., Gladwin, M. T. Mechanisms of nitrite bioactivation. Nitric Oxide 38, 58-68 (2014).

21. Srihirun, S., et al. Platelet inhibition by nitrite is dependent on erythrocytes and deoxygenation. PLoS ONE 7, e30380 (2012). https://doi.org/10.1371/journal.pone.0030380

22. Tsuchiya, K., et al. Malfunction of vascular control in lifestyle-related diseases: formation of systemic hemoglobin-nitric oxide complex (HbNO) from dietary nitrite. J. Pharmacol. Sci. 96, 395400 (2004).

23. Jia, L., Bonaventura, C., Bonaventura, J., Stamler, J. S. S-nitrosohemoglobin: a dynamic activity of blood involved in vascular control. Nature 380, 221-226 (1996).

24. Stamler, J. S., et al. Blood flow regulation by $S$-nitrosohemoglobin in the physiological oxygen gradient. Science 276, 2034-2037 (1997). 
25. Roche, C. J., Cassera, M. B., Dantsker, D., Hirsch, R. E., Friedman, J. M. Generating Snitrosothiols from hemoglobin mechanisms, conformational dependence, and physiological relevance. J. Biol. Chem. 288, 22408-22425 (2013).

26. Pawloski, J.R., Hess, D.T., Stamler, J.S. Export by red blood cells of nitric oxide bioactivity. Nature 409, 622-626 (2001).

27. Helms, C. C., Gladwin, M. T., Kin-Shapiro, D. B. Erythrocytes and vascular function: oxygen and nitric oxide. Front. Physiol. 9, 1-9 (2018).

28. Pernow, J., Mahdi, A., Yang, J., Zhou, Z. Red blood cell dysfunction: a new player in cardiovascular disease. Cardiovasc. Res. 115, 1596-1605 (2019).

29. Sun, C. W., et al. Hemoglobin $\beta 93$ cysteine is not required for export of nitric oxide bioactivity from the red blood cell. Circulation 139, 2654-2663 (2019).

30. Schmidt, H. H. H. W., Feelisch, M. Red blood cell-derived nitric oxide bioactivity and hypoxic vasodilation. To $\beta 93$ or not to $\beta 93$ ? Circulation 139, 2664-2667 (2019).

31. DeMartino, A. W., Kim-Shapiro, D. B., Patel, R. P., Gladwin, M. T. Nitrite and nitrate chemical biology and signaling. Br. J. Pharmacol. 176, 228-245 (2019).

32. Walthall, K., Cappon, G. D., Hurt,t M. E., Zoetis, T. Postnatal development of the gastrointestinal system: A species comparison. Birth Defects Res. B 74, 132-156 (2005).

33. Pun, P., et al. Changes in plasma and urinary nitrite after birth in premature infants at risk for necrotizing enterocolitis. Pediatr. Res. 79, 432-437 (2016).

34. Jones, J. A., Hopper, A. O., Power, G. G., Blood, A. B. Dietary intake and bio-activation of nitrite and nitrate in newborn infants. Pediatr. Res. 77, 173-181 (2015).

35. Thomas, D. D. Breathing new life into nitric oxide signaling: A brief overview of the interplay between oxygen and nitric oxide. Redox Biol. 5, 225-233 (2015).

36. Torres-Cuevas, I., et al. Oxygen and oxidative stress in the perinatal period Redox Biol. 12, 674$681(2017)$ 
37. Chobanyan-Jürgens, K., et al. Renal carbonic anhydrases are involved in the reabsorption of endogenous nitrite. Nitric Oxide 26, 126-131 (2012).

38. Kanady, J. A., et al. Nitrate reductase activity of bacteria in saliva of term and preterm infants. Nitric Oxide 27, 193-200 (2012).

39. Castellote, C., et al. Premature delivery influences the immunological composition of colostrum and transitional and mature human milk. J. Nutr. 141, 1181-1187 (2011).

40. Sohn, K., Kalanetra, K. M., Mills, D. A., Underwood, M. A. Buccal administration of human colostrum: impact on the oral microbiota of premature infants. Pediatr. Neonatal. 58, 534-540 (2017).

41. Subcommittee on Nutrition During Lactation, Committee on Nutritional Status During Pregnancy and Lactation, Food and Nutrition Board, Institute of Medicine, National Academy of Science. Nutrition During Lactation. National Academy Press, Washington, DC, 1991.

42. Iizuka, T., et al. Non-enzymatic nitric oxide generation in the stomach of breastfed neonates. Acta Pediatr. 88, 1053-1055 (1999).

43. Kanematsu, Y., et al. Dietary doses of nitrite restore circulating nitric oxide level and improve renal injury in L-NAME-induced hypertensive rats. Am. J. Physiol. Renal Physiol. 295, F1457-F1462 (2008).

44. 42. Hancock, J. T., et al. Antimicrobial properties of milk: dependence on presence of xanthine oxidase and nitrite. Antimicrob. Agents Chemother. 46, 3308-3310 (2002).

45. Cieslak, M., Ferreira, C. H. F., Shifrin, Y., Pan, J., Belik, J. Human milk $\mathrm{H}_{2} \mathrm{O}_{2}$ content: does it benefit preterm infants? Pediatr. Res. 83, 687-692 (2018).

46. Li, H., Samouilov, A., Liu, X., Zweier, J. L. Characterization of the magnitude and kinetics of xanthine oxidase-catalyzed nitrate reduction: evaluation of its role in nitrite and nitric oxide generation in anoxic tissues. Biochemistry 42, 1150-1159 (2003).

47. Stevens, C. R., et al. Antibacterial properties of xanthine oxidase in human milk. Lancet 356, 829830 (2000).

48. Harrison, R. Milk xanthine oxidase: properties and physiological roles. Int. Dairy J. 16, 546-554 (2006). 
49. Latchaw, L. A., Jacir, N. N., Harris, B. H. The development of pyloric stenosis during transpyloric feedings. J. Pediatr. Surg. 24, 823-824 (1989).

50. Panteli, C. New insight into the pathogenesis of infantile pyloric stenosis. Pediatr. Surg. Int. 25, 1043-1052 (2009).

51. Krogh, C., et al. Familial aggregation and heritability of pyloric stenosis. JAMA 303, 2393-2399 (2010).

52. Huang, L. T., Tiao, M. M., Lee, S. Y., Hsieh, C. S., Lin, J. W. Low plasma nitrite in infantile hypertrophic pyloric stenosis patients. Dig. Dis. Sci. 51, 869-872 (2006).

53. Huang, P. L., Dawson, T. M., Bredt, D. S., Snyder, S. H., Fishman, M. Targeted disruption of the neuronal nitric oxide synthase gene. Cell 75, 1273-1286 (1993).

54. Chung, E., et al. Genetic evidence for the neuronal nitric oxide synthase gene (NOS19 as a susceptibility locus for infantile pyloric stenosis. Am. J. Hum. Genet. 58, 363-370 (1996).

55. Barbosa, I. M., Ferrante, S. M., Mandarim-De-Lacerda, C. A. Role of nitric oxide synthase in the etiopathogenesis of hypertrophic pyloric stenosis in infants. J. Pediatr. 77, 307-312 (2001).

56. Kusafuka, T., Puri, P. Altered messenger RNA expression of the neuronal nitric oxide synthase gene in infantile hypertrophic pyloric stenosis. Pediatr. Surg. Int. 12, 576-579 (1997).

57. Wayne, C., et al. Formula-feeding and hypertrophic pyloric stenosis: is there an association? A case-control study. J. Pediatr. Surg. 51, 779-782 (2016).

58. Krogh, C., Biggar, R. J., Fischer, T. K., Lindholm, M., Wohlfahrt, J. Bottle-feeding and the risk of pyloric stenosis. Pediatrics 130, e943-e949 (2012).

59. Neu, J., Walker, W. A. Necrotizing enterocolitis. N. Eng. J. Med. 364, 255-264 (2011).

60. Gephart, M. S. M., McGrath, J. M., Effken, J. A., Halpern, M. D. Necrotizing enterocolitis risk: state of the science. Adv. Neonatal Care 12, 77 (2012).

61. Patel, R. M., Denning, P. W. Intestinal microbiota and its relationship with necrotizing enterocolitis. Pediatr. Res. 78, 232-238 (2015). 
62. Bazacliu, C., Neu, J. Pathophysiology of necrotizing enterocolitis: An update. Curr. Pediatr. Rev. 15, 68-87 (2019).

63. Yazji, I., et al. Endothelial TLR4 activation impairs intestinal microcirculatory perfusion in necrotizing enterocolitis via eNOS-NO-nitrite signaling. Proc. Natl. Acad. Sci. USA. 110, 9451-9456 (2013).

64. Mally, P., et al. Association of necrotizing enterocolitis with elective packed red cell transfusions in stable, growing, premature neonates. Am. J. Perinatol. 23, 451-458 (2006).

65. Reynolds, J. D., et al. $S$-nitrosohemoglobin deficiency: A mechanism for loss of physiological activity in banked blood. Proc. Natl. Acad. Sci. USA. 104, 17058-17062 (2007).

66. Azarov, I., et al. Nitric oxide scavenging by red blood cells as a function of hematocrit and oxygenation. J. Biol. Chem. 280, 39024-39032 (2005).

67. Cortese-Krott, M. M., et al. Human red blood cells at work: identification and visualization of erythrocytic eNOS activity in health and disease. Blood 120, 4229-4237 (2012).

68. Sanchez, C. M., et al. Relationship between packed red blood cell storage time and arginase concentration: 6AP5-6. Eur. J. Anaesthesiol. 28, 92 (2011).

69. Yang, J., Gonon, A. T., Sjöquist, P. O., Lundberg, J. O., Pernow, J. Arginase regulates red blood cell nitric oxide synthase and export of cardioprotective nitric oxide bioactivity. Proc. Natl. Acad. Sci. USA. 110, 15049-15054 (2013).

70. Patel, R. M., et al. Association of red blood cell transfusion, anemia, and necrotizing enterocolitis in very low-birth-weight infants. JAMA 315, 889-897 (2016).

71. Dezfulian, C., Raat, N., Shiva, S., Gladwin, M. T. Role of the anion nitrite in ischemia-reperfusion cytoprotection and therapeutics. Cardiovasc. Res. 75, 327-338 (2007).

72. Rassaf, T., Ferdinandy, P., Schulz, R.. Nitrite in organ protection. Br. J. Pharmacol. 171, 1-11 (2014).

73. Blood, A. B. The medicinal chemistry of nitrite as a source of nitric oxide signaling. Curr. Top. Med. Chem. 17, 1758-1768 (2017). 
74. Totzeck, M., Hendgen-Cotta, U. B., Rassaf, T. Nitrite-Nitric Oxide Signaling and Cardioprotection. Adv. Exp. Med. Biol. 982, 335-346 (2017).

75. Ibrahim, Y. I., et al. Inhaled nitric oxide therapy increases blood nitrite, nitrate, and Snitrosohemoglobin concentrations in infants with pulmonary hypertension. J. Pediatr. 160, 245-251 (2012).

76. Bloch, K. D., Ichinose, F., Roberts, Jr. J. D., Zapol, W. M. Inhaled NO as a therapeutic agent. Cardiovasc. Res. 75, 339-348 (2007).

77. Jones, J. A., et al. Nitrite and nitrate concentrations and metabolism in breast milk, infant formula, and parenteral nutrition. JPEN J. Parenter. Enteral Nutr. 38, 856-866 (2014). 


\section{Acknowledgements}

I would like to thank Editage (www.editage.com) for English language editing.

\section{FIGURE LEGENDS}

\section{Figure 1.}

\section{Nitrite pool and interactions with the transport of NO activities.}

There are two major sources of nitrite in the whole blood and tissues (nitrite pool): endogenous nitrite following the oxidation of NOS-derived NO as well as dietary nitrite via the enterosalivary pathway. The nitrite in the pool is transduced to NO bioactivity by circulating and tissue-bound nitrite reductases in hypoxia and acidosis. Erythrocytes function as physiological transporters of NO bioactivity. Deoxygenated $\mathrm{Hb}$ possesses nitrite reductase activity and reduces nitrite to NO during artery-to-vein transit, followed by the formation of $\mathrm{Fe}-\mathrm{NO} \mathrm{Hb}$ in the erythrocytes and subsequent $\mathrm{NO}$ release to other thiol acceptors to form plasma and other cellular SNOs for systemic NO bioactivity.

$\mathrm{NO}$, nitric oxide; eNOS, endothelial nitric oxide synthase; Hb, hemoglobin; oxyHb, oxygenated hemoglobin; deoxyHb, deoxygenated hemoglobin; Fe-NO Hb, iron nitrosyl hemoglobin; SNOs, $S$ nitrosothiols.

\section{Figure 2.}

\section{Plasma nitrite concentrations in fetal sheep at birth.}

Within 15 min following birth, plasma nitrite concentrations fell after umbilical cord ligation and ventilation initiation by more than $60 \%(* \mathrm{P}<0.001$ compared with baseline) and remained lower than baseline, 60, 120, and $180 \mathrm{~min}$ after birth. Figure adapted from reference (33).

\section{Figure 3.}

Physiological factors that reduce nitrite-mediated NO bioactivity in neonates.

\section{Figure 4.}

\section{Intragastric generation of $\mathrm{NO}$ in neonates.}

In total, 149 samples of gas were collected from the stomachs of 31 healthy, full-term neonates. The concentrations of NO in gases collected from the lumen of the neonatal stomach were measured using a NO chemiluminescence analyzer. Infants were divided into 2 groups: A $(n=17)$, fed on breast milk only; $\mathrm{B}(\mathrm{n}=14)$, fed on formulas with/without supplementary breast milk. The incidence of abnormally high concentrations of $\mathrm{NO}>7.72 \mathrm{ppm}(\mathrm{M} \pm 2 \mathrm{SD})$ and the average peak levels in Group A were significantly higher than those in Group B. Each line represents one individual. Figure adapted from reference (42). 
Figure 1

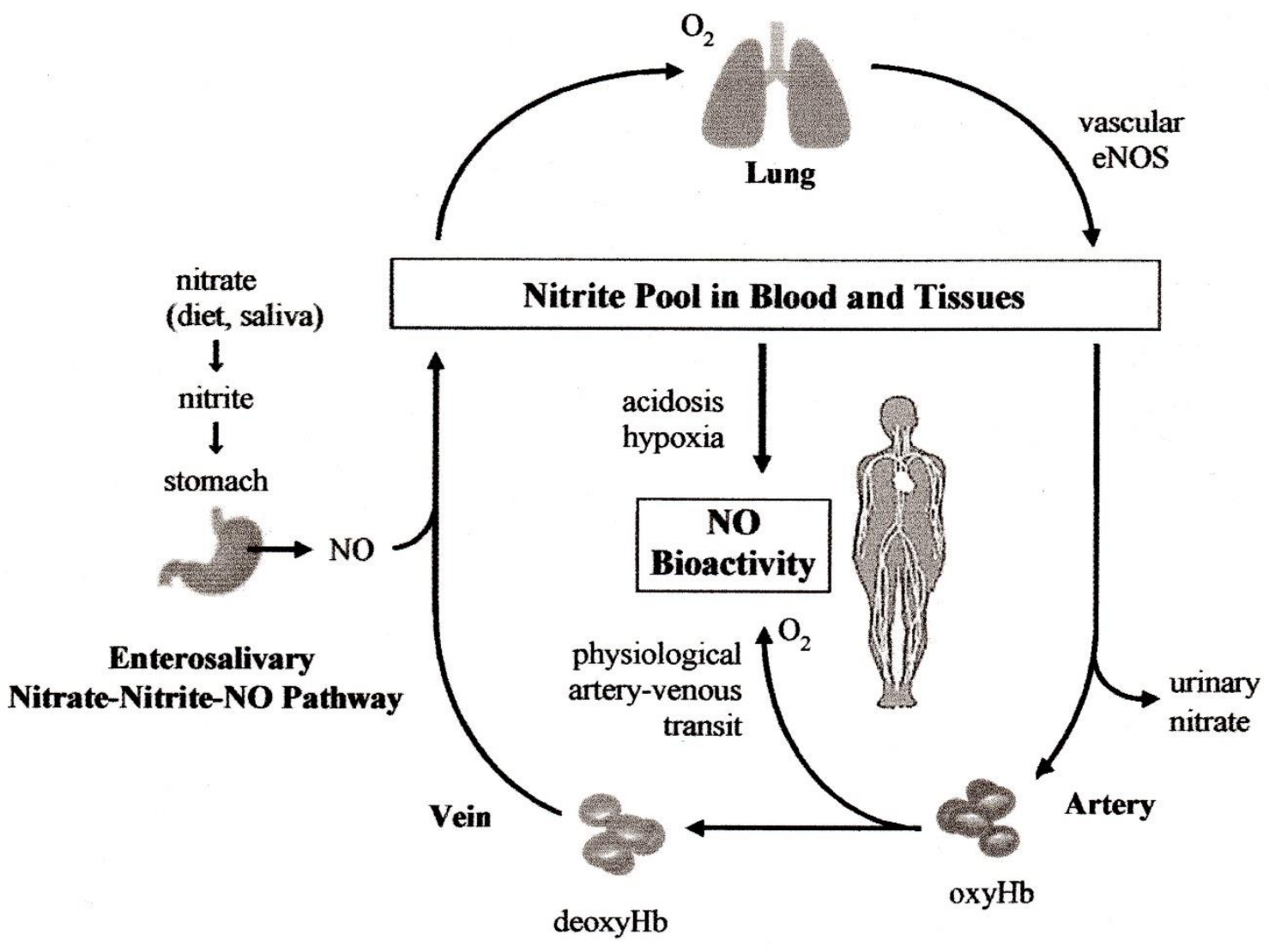


Figure 2

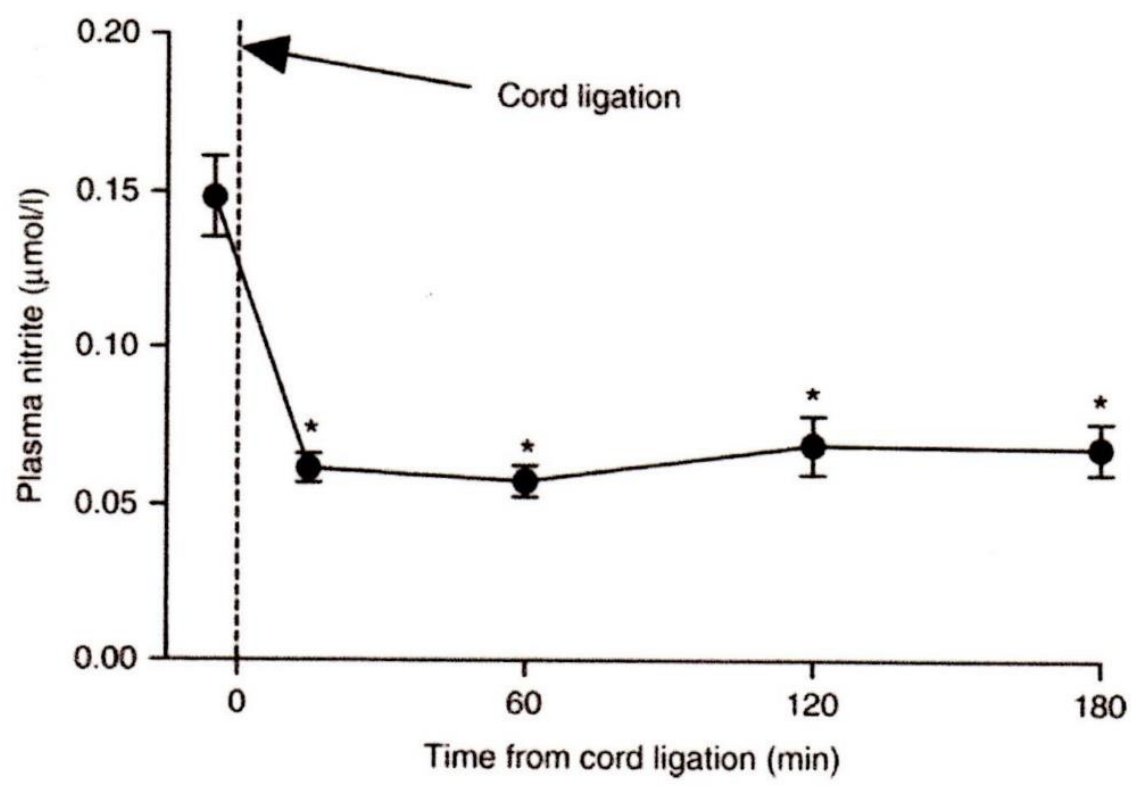


Figure 3

Nitrate levels in milk and formula are lower than those in foods in adulthood.

The saliva production rates are lower in neonates than adults.

Nitrate reduction to nitrite in the oral cavity by commensal bacteria is less in neonates than adults.

The neonate stomach produces much less NO from swallowed nitrite than that in adults.

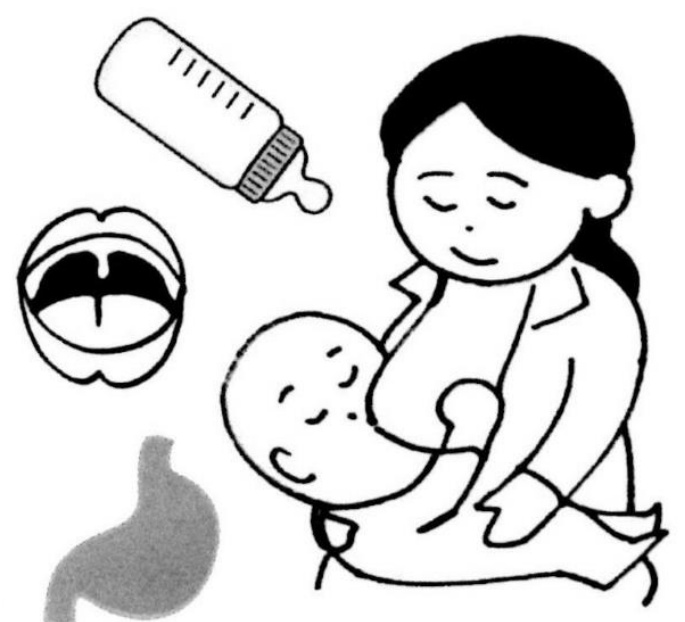

The urinary nitrite concentrations of neonates are higher than those of the adults. 
Figure 4

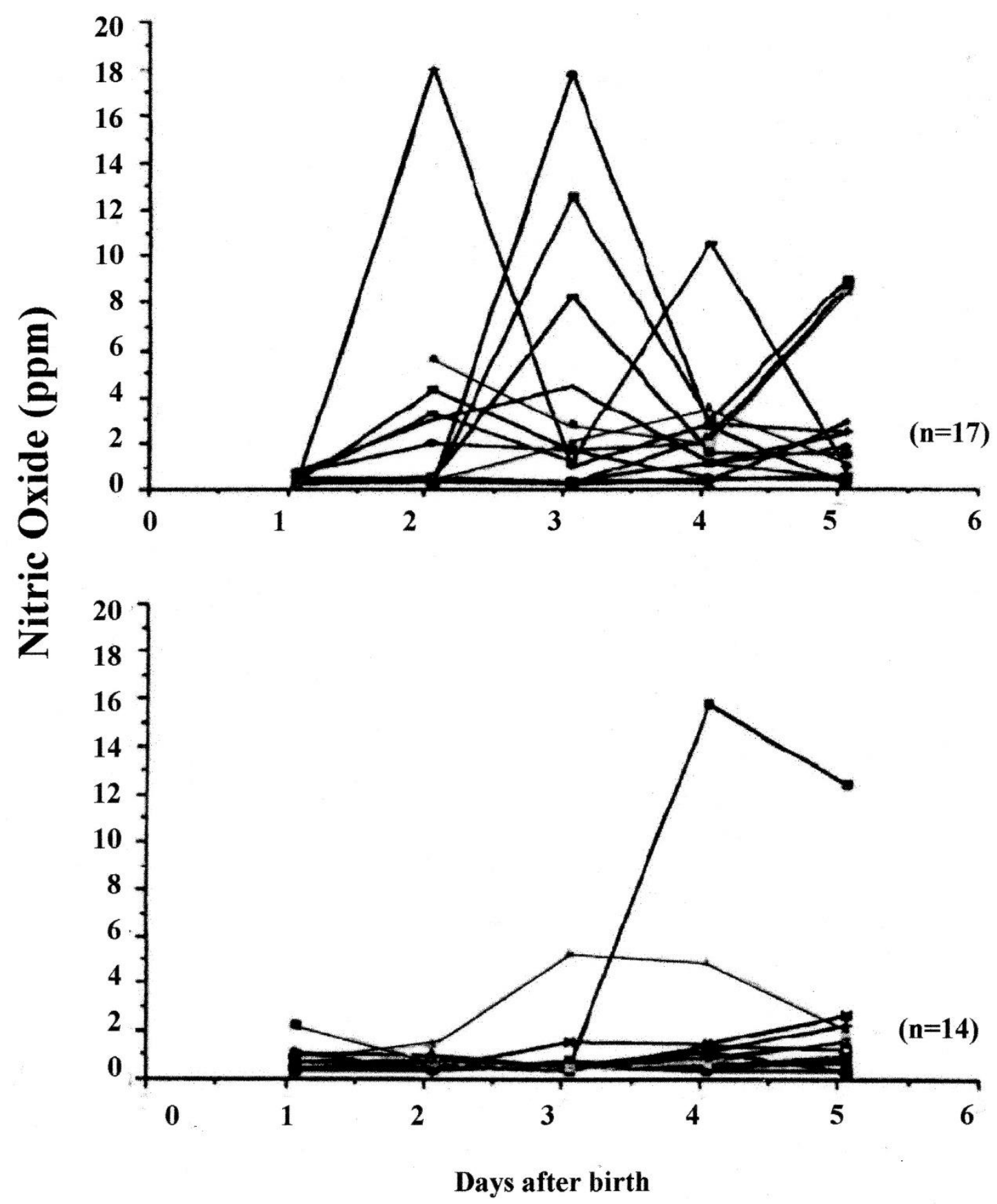




\section{Table 1}

Nitrate and nitrite concentrations in human milk and daily consumption during lactation

\begin{tabular}{ccccc}
\hline Stage & $\begin{array}{c}\text { Nitrate } \\
(\mathrm{mg} / 100 \mathrm{~mL})\end{array}$ & $\begin{array}{c}\text { Nitrite } \\
(\mathrm{mg} / 100 \mathrm{~mL})\end{array}$ & $\begin{array}{c}\text { Nitrate } \\
(\mathrm{mg} / 750 \mathrm{~mL})\end{array}$ & $\begin{array}{c}\text { Nitrite } \\
(\mathrm{mg} / 750 \mathrm{~mL})\end{array}$ \\
\hline Colostrum & $0.19 \pm 0.03$ & $0.08 \pm 0.02$ & $1.43 \pm 0.24$ & $0.60 \pm 0.15$ \\
Transition & $0.52 \pm 0.10$ & $0.001 \pm 0.001$ & $3.90 \pm 0.75$ & $0.008 \pm 0.008$ \\
Mature & $0.31 \pm 0.02$ & $0.001 \pm 0.001$ & $2.32 \pm 0.21$ & $0.008 \pm 0.008$ \\
\hline
\end{tabular}

The sample means were based on 12-50 individual samples in triplicate. The daily intake of nitrate and nitrite was calculated as $750 \mathrm{~mL}$ of intake/day. Table is reproduced from reference (2). 


\section{Table 2}

Comparison of the concentrations and daily intakes of nitrite among breast and formula milk in humans and drinking water in a rat model

\begin{tabular}{llrr}
\hline & & \multicolumn{2}{c}{ Nitrite } \\
\cline { 3 - 4 } & ADI & $\begin{array}{c}\text { Concentrations } \\
(\mathrm{mg} / 100 \mathrm{~mL})\end{array}$ & $\begin{array}{c}\text { Daily intake } \\
(\mathrm{mg} / \mathrm{kg} \text { BW/day })\end{array}$ \\
\hline \multirow{2}{*}{ Hord (human) } & Colostrum & $0.08 \pm 0.02$ & 0.06 \\
\cline { 2 - 4 } & Transition-mature & $0.001 \pm 0.001$ & 0.2 \\
\hline \multirow{2}{*}{ Iizuka (human) } & Colostrum & $0.2 \pm 0.024$ & 0.0027 \\
\cline { 2 - 4 } & Formula & $0.065 \pm 0.024$ & 0.5 \\
\hline \multirow{2}{*}{ Kanematsu (rat) } & & 0.1 & 0.16 \\
\cline { 2 - 4 } & & 1.0 & 0.1 \\
\hline
\end{tabular}

The daily intake of nitrite $(\mathrm{mg} / \mathrm{kg} \mathrm{BW} /$ day) was calculated as $3.0 \mathrm{~kg}$ of BW and $750 \mathrm{~mL}$ of intake/day in humans and $300 \mathrm{~g}$ of BW and $30 \mathrm{~mL}$ of water intake/day in rats. BW, body weight; ADI, acceptable daily intake. Table is reproduced from references (2), (40), and (41). 